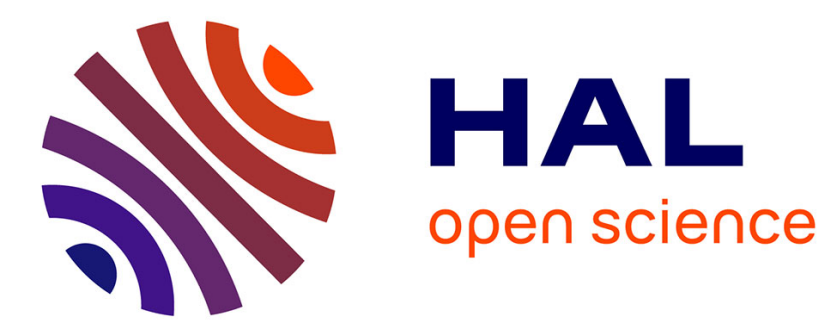

\title{
F-formations and Collaboration Dynamics Study for Designing Mobile Collocation
}

Audrey Serna, Simon Pageaud, Lili Tong, Sébastien George, Aurélien Tabard

\section{To cite this version:}

Audrey Serna, Simon Pageaud, Lili Tong, Sébastien George, Aurélien Tabard. F-formations and Collaboration Dynamics Study for Designing Mobile Collocation. 18th International Conference on Human-Computer Interaction with Mobile Devices and Services Adjunct (MobileHCI 2016) , Sep 2016, Florence, Italy. pp.1138-1141, 10.1145/2957265.2962656 . hal-01387991

\section{HAL Id: hal-01387991 https://hal.science/hal-01387991}

Submitted on 26 Oct 2016

HAL is a multi-disciplinary open access archive for the deposit and dissemination of scientific research documents, whether they are published or not. The documents may come from teaching and research institutions in France or abroad, or from public or private research centers.
L'archive ouverte pluridisciplinaire HAL, est destinée au dépôt et à la diffusion de documents scientifiques de niveau recherche, publiés ou non, émanant des établissements d'enseignement et de recherche français ou étrangers, des laboratoires publics ou privés. 


\section{F-formations and Collaboration Dynamics Study for Designing Mobile Collocation}

\author{
Audrey Serna \\ Université de Lyon, CNRS \\ INSA-Lyon, LIRIS, UMR5205 \\ F-69621, France \\ audrey.serna@insa-lyon.fr \\ Lili Tong \\ Université de Lyon, CNRS \\ INSA-Lyon, LIRIS, UMR5205 \\ F-69621, France \\ lili.tong@insa-lyon.fr \\ Simon Pageaud \\ Université de Lyon, CNRS \\ Université Lyon 1, LIRIS, \\ UMR5205 \\ F-69622, France \\ simon.pageaud@univ-lyon1.fr \\ Sébastien George \\ Université du Maine, \\ Le Mans, France \\ sebastien.george@univ-lemans.fr \\ Aurélien Tabard \\ Université de Lyon, CNRS \\ Université Lyon 1, LIRIS, \\ UMR5205 \\ F-69622, France \\ aurelien.tabard@univ-lyon1.fr \\ Permission to make digital or hard copies of part or all of this work for \\ personal or classroom use is granted without fee provided that copies are \\ not made or distributed for profit or commercial advantage and that \\ copies bear this notice and the full citation on the first page. Copyrights \\ for third-party components of this work must be honored. For all other \\ uses, contact the Owner/Author. \\ Copyright is held by the owner/author(s). \\ MobileHCI '16 Adjunct, September 06-09, 2016, Florence, Italy \\ ACM 978-1-4503-4413-5/16/09. \\ http://dx.doi.org/10.1145/2957265.2962656
}

\begin{abstract}
Mobile devices offer great opportunities in the field of collaborative learning for providing digital information while still supporting social interactions between group members. We designed and tested an orienteering mobile learning game to better understand how device use shaped collaboration in highly mobile conditions. The study involved four groups of three students all equipped with tablets. We focused our analysis on the relationship between participants' arrangements (Fformations), their device usage and coordination mechanisms (i.e. awareness, regulation, information sharing, and discussion). Our results emphasize the importance of considering the transitions between arrangements. From these observations we derive recommendations for the design of relevant interactions techniques for mobile collaborative activities.
\end{abstract}

\section{Author Keywords}

Collaboration; Coordination; F-formation; Collaboration dynamics; Group regulation; Ubiquitous computing; Mobile learning.

\section{ACM Classification Keywords}

H.5.3. Information interfaces and presentation (e.g., $\mathrm{HCI}$ ): Group and Organization Interfaces - Computersupported cooperative work; K.3.1 Computing Milieux: Computer Uses in Education - Collaborative learning. 
We consider coordination as "the act of managing interdependencies between activities performed to achieve a goal" [3]. In coordinated work, participants act towards a shared goal dealing with time and organizational constraints. For our study purpose, we selected four mechanisms used in the process of coordination: awareness, regulation, information sharing and discussion.

\begin{tabular}{|c|c|c|c|}
\hline \multicolumn{4}{|c|}{ Collective activity } \\
\hline Colla & boration & Coope & peration \\
\hline \multicolumn{4}{|c|}{ Coordination } \\
\hline Awareness & Regulation & $\begin{array}{c}\text { Information } \\
\text { sharing }\end{array}$ & Discussion \\
\hline
\end{tabular}

Table 1: Hierarchical levels in collective activity

\section{Introduction}

The physical and digital properties of our environment shape the organization and interaction in collaboration [5]. In this article, we are especially interested in understanding the relationship between mobility and coordination mechanisms in mobile and collaborative outdoor activities.

To study how device use and spatial arrangements shape coordination in real conditions, we designed and deployed an orienteering learning game with the collaboration of high school teachers. We conducted an experiment with four groups of three students, aged from 16 to 17 . During the experiment, one teacher and one person from our research team followed each group to supervise and film the group activity. For the video analysis, our observations focused on four elements: awareness, regulation, information sharing and discussions among group members. We use Kendon's F-formations [2] to analyze people's spatial-orientational arrangements in joint activities, with a focus on how F-formations are created during the collaboration and what are the social interactions happening in these arrangements.

Our study offers insights on how students use tablets to collaborate in an outdoor activity, the Fformations associated to specific coordination phases, and the importance of transitions. We derive implications for design, in respect to complex information sharing and control in proxemics interaction in mobile conditions.

\section{Observed F-formations}

Kendon [2] described three types of F-formation for groups of two persons: L-shaped, face-to-face and side-by-side (see Figure 1, top), and he added a circular F-formation arrangement for groups of more than two persons. Marshall et al. [5] added two more arrangements for groups of four persons: semi-circular and rectangle. In our study, the groups are composed of three students, we noticed three main types of Fformations arrangements: semi-circular, circular and triangular (see Figure 1, bottom). These arrangements can be influenced by the on-going task, and also by environmental features. Given the mobile nature of the activity, compared to the F-formations described in the $\mathrm{HCI}$ literature, the F-formations we observed were highly dynamic. Both within the formation, for example students would keep their formation but move in the same direction, or all rotate at once; and also moving quickly from one formation to another. A transition from one formation to another often indicated a change of the focus in the on-going task.

The triangular arrangement happened when two students were standing close to each other on one side with a third student staying on the opposite side at some distance from the others. 


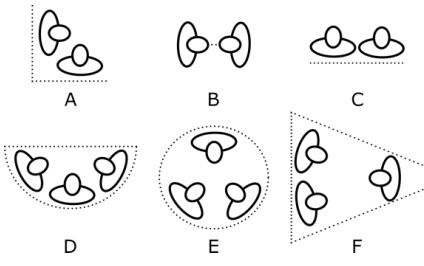

Figure 1. F-formation arrangements.

A. L-shaped; B. face-to-face; C. side-by-side; D. semi-circular E. circular; F. triangular.
This arrangement is often caused by an unequal distribution of action. The triangular arrangement was rarely maintained for a long time. In the circular arrangement, students are at a similar distance from each other, it appeared to be the most comfortable position to have a group talk. The circular arrangement was the most stable formation we observed, and also the most frequent one (especially for discussion). Finally, in the semi-circular arrangement, three students stay corner-to-corner, which let them easily share objects, such as a tablet or an instrument.
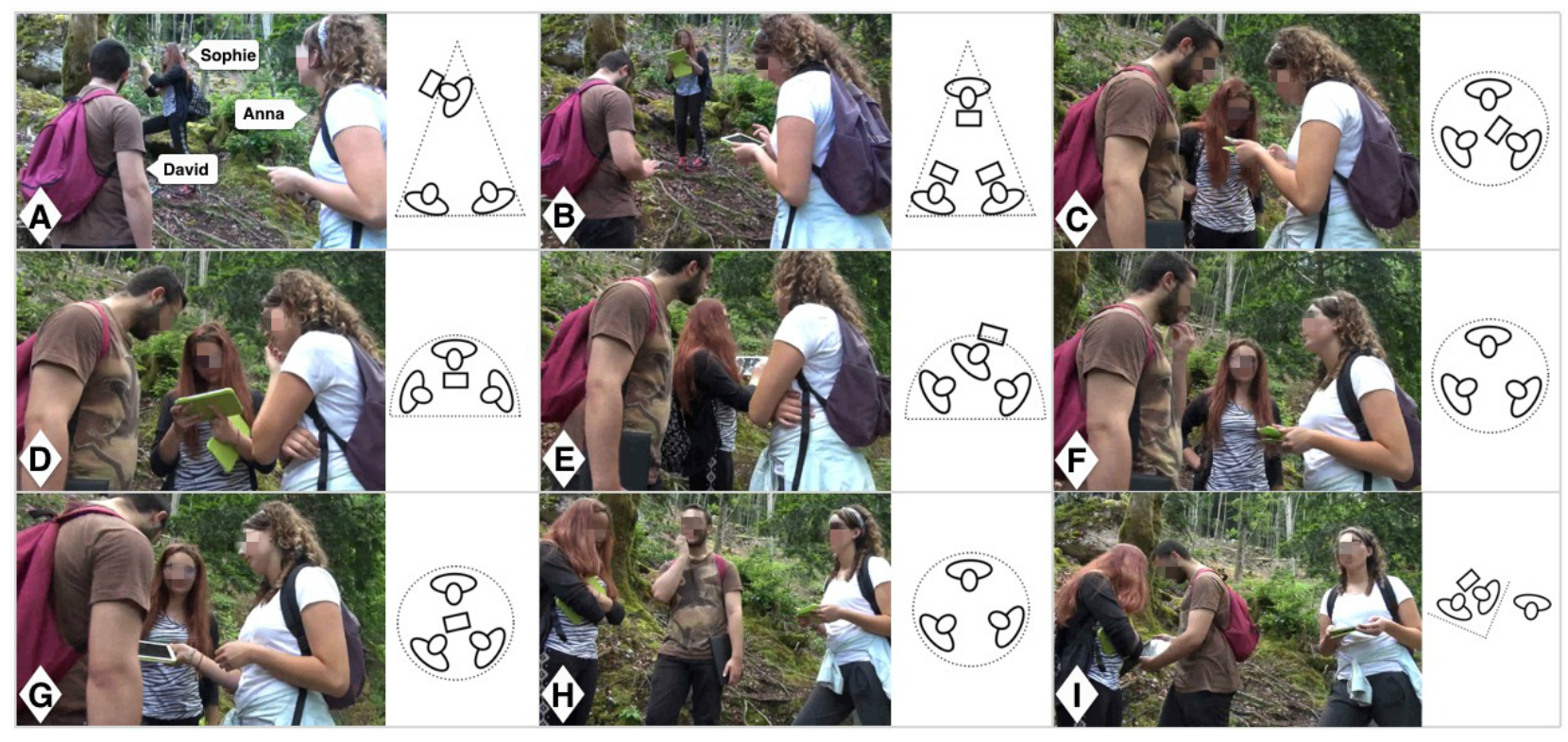

Figure 2: A sequence of collaborative behaviors and their corresponding F-formations. A: Sophie is scanning a QR code, David and Anna are watching (awareness); B: Sophie reads out code to others (verbal information sharing); C: David and Sophie move towards Anna to see her tablet (awareness \& regulation); D: Sophie takes Anna's tablet (on-device information sharing); E: Sophie holds up her tablet showing it to the others (on-device information sharing); F: They are discussing (discussion); G: David double checks the tablet (on-device information sharing); H: During the discussion, Anna suggests to move forward (discussion \& regulation); I: Sophie asks David where to go next (regulation \& on-device information sharing) 


\section{Implication for interaction design for mobile collocation}

Better support for complex information sharing

Sharing complex information was challenging and frequently led to new group arrangements to cope with the lack of shared ground. In such situations three people focusing on a single tablet is burdensome and impedes collaboration. There is a need for tools enabling collaborative interaction with complex information in mobile conditions. For instance, in semicircular formations, we could use proximity to enable information transfers between tablets, as proposed by Marquadt [4]. We could also enable the duplication of screens for a moment, or enable a focused/zoomed-in mode so that information is more readily visible to people in a circle.

Focusing on transitions between F-formations

Most of the arrangements we observed were only stable for short amounts of time. When designing tools to better support collaboration, rather than capturing given F-formations, emphasis should be given to changes between arrangements. For instance, the transition from one formation to another could be proactively managed on the devices by suggesting which device configuration would be most useful. Another possibility would be to let users to maintain the state of a previous configuration even though the arrangement has changed.

Subtlety and control in proxemic interaction

Leveraging proxemics to support users' interactions in context aware systems is promising, but should be treated with care in mobile conditions. Especially in outdoor conditions, the cost of implicit adaptations might not be worth the benefits. We observed many situations in which the arrangements of the participants were similar but the high level activity required different information and devices configurations.

\section{Acknowledgements}

This work was partially funded by the China Scholarship Council PhD program and the ANR project JENlab (ANR13-APPR-0001).

\section{References}

1. Paul Marshall, Yvonne Rogers, and Nadia Pantidi. 2011. Using F-formations to analyse spatial patterns of interaction in physical environments. In Proceedings of the ACM 2011 conference on Computer supported cooperative work (CSCW '11), 3033-3042.

2. Adam Kendon. 1990. Conducting interaction. Patterns of behaviour in focused encounters. Vol. 7. CUP Archive.

3. Thomas W. Malone and Kevin Crowston. 1990. What is coordination theory and how can it help design cooperative work systems? In Proceedings of the 1990 ACM conference on Computersupported cooperative work (CSCW '90), ACM, New York, NY, USA, 357-370.

4. Nicolai Marquardt, Ken Hinckley, and Saul Greenberg. 2012. Cross-device interaction via micro-mobility and f-formations. In Proceedings of the 25th annual ACM symposium on User interface software and technology (UIST '12), ACM, New York, NY, USA, 13-22.

5. Paul Marshall, Yvonne Rogers, and Nadia Pantidi. 2011. Using F-formations to analyse spatial patterns of interaction in physical environments. In Proceedings of the ACM 2011 conference on Computer supported cooperative work (CSCW '11), 3033-3042. 